\title{
The adenoid cystic carcinoma of the Bartholin's gland: a literature review
}

\author{
Antonio Cassio Assis Pellizzon
}

\begin{abstract}
The adenoid cystic carcinoma (ACC) of the Bartholin's gland (BG) is one of the most uncommon variant of vulvar malignancies representing only $10-15 \%$ of cases. The main differential diagnosis is the BG cyst. Risk factors to the development of ACCBG are still unclear. The symptoms are usually non-specific and may include local inflammation, pain, local itching, burning sensations, bleeding, pruritus and or dyspareunia. There is currently no consensus regarding the optimal surgical treatment and the question whether to do or not a systematic inguinal femoral lymph node dissection is still controversial. Guidelines for postoperative chemotherapy or chemoradiotherapy are not established, despite the relative frequency of microscopically positive surgical resection margin. Adjuvant radiation therapy seems to lower the incidence of local recurrence in patients with positive resection margins, based on retrospective studies and case reports. Chemotherapy as adjuvant treatment is still under evaluation.
\end{abstract}

Keywords: Adenoid cystic carcinoma, Bartholin's gland, Surgery, Radiotherapy, Chemotherapy, Surgical margins

\section{Background}

Primary neoplasms of the Bartholin's gland (BG) are rare, accounting for approximately $2-7 \%$ of vulvar cancer $[1,2]$. The tumor is accepted being a primary tumor of the Bartholin gland when: a- the tumor involving the area of the Bartholin gland is histologically compatible with the origin from the Bartholin gland; b- areas of apparent transition from normal elements to neoplastic ones are found in histologic study and c- there is no evidence of primary tumor elsewhere [3].

The adenoid cystic carcinoma (ACC) occurs primarily in the salivary glands, but many other anatomical locations, such as the respiratory tract, the nasopharynx, the breast and the uterus can also be affected [4]. ACC is one of the most uncommon variant of BG malignancies representing only $10-15 \%$ of cases [2].

\section{Differential diagnosis}

The differential diagnosis of ACCBG is the BG cysts, as most of the lesions look like a cyst or an inflammatory mass, or as an abscess of Bartholin's gland that do not respond following treatment [5].

\section{Correspondence: acapellizzon@accamargo.org.br}

Department of Radiation Oncology, AC Camargo Cancer Center, Rua Prof Antonio Prudente, 211, Sao Paulo 01509-020, Brazil

\section{Risk factors}

Risk factors to development of ACCBG are still unclear. Pure ACCBG appears to be unrelated to high-risk HPV and the mechanisms by which normal cells give rise to an HPV-unrelated ACC remain largely unknown. Recent studies have demonstrate that chromosomal translocation involving the genes encoding the transcription factors MYB and NFIB functions as a driving force of ACC development regardless of anatomic site of origin. Xing et al. used in situ fluorescence hybridization and confirmed that chromosome translocations involving $N F I B$, but with an intact MYB, indicate the presence of novel oncogenic mechanisms for the development of ACCBG [6-8].

Hormonal changes may also play a role in the development of ACCBG. According to Copeland et al., seven of 14 patients aged below 42 years had their ACCBG diagnosed in association with pregnancy, when dramatic hormonal changes happen [3].

\section{Symptoms}

ACCBG is slow growing lesion similarly to ACC that occur more frequently in salivary glands, skin and upper respiratory tract [9]. The symptoms are usually nonspecific and may include local inflammation, pain, bleeding, pruritus and or dyspareunia [10]. Other symptoms 
as local itching and burning sensations, due to infiltration of perineural spaces, can precede the presence of a palpable mass [11].

\section{Pretreatment evaluation}

Pretreatment evaluations generally include CT scan of the chest, abdomen and pelvis. The CT can also be useful to evaluate nodal spread in the pelvis in women with clinically evidence of groin node metastasis or deeply invasive local lesions. The primary tumor generally appears as a non specific soft tissue mass [12].

MRI can also be useful for the preoperative staging and evaluation of resectability of these tumors. According to Downs et al. the lesions typically show a relatively high intensity appearance on T2-weighted images and invasions into the urethra or into the rectum can be easily identified in more advanced lesions. MRI can also be used to evaluate lymphatic spread and to follow up, differentiating recurrences from post-therapy local or regional changes [13].

Bone scans are generally used to rule out osseous metastases in more advanced cases and the positron emission tomography (PET) can provide additional information for the initial staging. Unfortunately due to the rarity of the disease and paucity of published data on the use of PET, its impact on survival and local control has been not established yet [14].

\section{Histology}

Bartholin's neoplasm may arise from the gland itself or from its duct. Microscopically, ACCBG is composed of uniform and small cells arranged in cords and nests with a cribriform pattern, often surrounding acellular spaces containing variable amounts of mucin and hyalinized material. In addition, solid cellular and tubulo-glandular patterns of similar cell types are present. The tumor cells are small and basaloid, with little cytoplasm and regular nuclear structure. Residual normal BG elements with areas suggestive of transition into neoplastic tissue can also be observed [3].

\section{Treatment}

There is currently no consensus regarding the optimal surgical treatment for ACCBG due to the limited number of cases and lack of prospective and randomized controlled trials in the literature [11]. Both, simple excision and radical vulvectomy with or without lymph node dissection have described in the literature, but it is often observed that ACCBG has propensity towards local recurrence despite negative margins with late clinical presentation of recurrence and distant metastasis. Anaf et al. noted a higher risk of local recurrence (43\% versus $9 \%$ ) in a group of 43 patients with ACCBG when local excision was compared to radical vulvectomy [15]. A review by Yang et al. showed that $68.9 \%$ of patients who had a simple excision had recurrences compared with $42.9 \%$ of patients who had a radical vulvectomy. Although the information on the status of margins at the initial surgery was incomplete, the positivity of resection margin was $48 \%$ in the simple excision group and $30 \%$ in the radical vulvectomy group [16]. Conversely, Wang et al. [17] and Korkontzelos et al. [18] reported single cases and conducted a literature reviews suggesting that initial conservative surgery with wide local lesion, even for later stage patients, can be considered in most instances. According to the experience of Lelle et al. [19] if an adequate surgical margin can be achieved, a more conservative surgical procedure with adjuvant radiation may be reasonable approach, instead of a radical vulvectomy. A publication of Copeland et al. [3] showed that patients with ACCBG treated with wide local excision and clear margins have an expected 5-, 10- and 15- year progression-free and survival rates of $47 \%, 71 \%, 38 \%, 50 \%, 13 \%$ and $51 \%$, respectively.

A review by Alsan et al. confirmed that clear margin is an important prognostic factor, and not the extent of surgery. In their report simple and radical vulvectomy had been performed in $54 \%$ and $46 \%$ of cases, respectively. Local recurrences were observed in $35 \%$ of cases with positive resection margins and in only $10 \%$ of those with clear resection margins [20].

\section{Lymph node dissection}

The question whether to do or not a systematic inguinal femoral lymph node dissection is still controversial. The lymphatic dissemination of ACCBG appears to be different from other carcinomas of BG. Metastatic disease to the inguinal-femoral nodes is uncommon. Most of the authors consider that it must be realized just in case of suspicion of nodal involvement by metastasis. Anaf et al. [15] confirmed it, as in only 2 cases out of 22 patients with performed lymphadenectomy, metastases to lymph nodes occurred. Clinical and radiological lymph node involvement, now including PET evaluations are recommended, specially for advanced or recurrent disease, because this histological type tends to metastasize before giving locoregional lymph node metastasis $[15,16,21]$.

\section{Adjuvant therapy}

Guidelines for postoperative chemotherapy and chemoradiotherapy are not established, despite the frequency of microscopically positive surgical resection margin relatively high. Adjuvant radiation therapy seems to lower the incidence of local recurrence in patients with positive resection margins. Rosenberg et al. [22] and Copeland et al. [3] reported the benefits of postoperative external beam radiation for patients with positive margins. Other adverse prognostic factor for local 
recurrence reported by Alsan et al. [20] is the presence of neural invasion.

Agolli et al. described the case of a 54-year-old woman with locally advanced ACCBG treated with surgery and adjuvant radiotherapy, with 56 Gy given in 28 fractions, the same dose level used for adjuvant treatment of other anatomical sites affected [23]. Takatori et al. [24] also published a case report of a patient with positive resection margin who received adjuvant chemoradiotherapy. The dose of radiotherapy given to the whole pelvis was 59.4 Gy in 33 fractions combined with CPT-11.

According to a recent publication approximately $40 \%$ of the patients need adjuvant radiotherapy after primary surgery and $8 \%$ of the BG neoplasms are not surgical candidates [25].

Radiation treatment options included teletherapy combined with a boost to the primary site, regional nodes and/or interstitial brachytherapy.

Reported chemotherapy regimens in adjuvant setting or palliation include a variety of drugs used as methotrexate, dactinomycin, doxorubicin, cyclophosphamide and cisplatin, isolated or in combination. However, all of these regimens tend to induce substantial hematologic as well as non-hematologic toxicities. A report on the successful use of chemoradiotherapy with irinotecan for a patient with positive margin instead of a new resection was published by Takatori et al. [24].

An old report by Sugiyama et al. reported the efficacy in local control of radiotherapy concurrent to 5fluorouracil [26].

\section{Distant metastasis}

The most frequent metastatic site is the lung $[4,16,27,28]$. Bernstein et al. [1] noted that 5 of 20 patients died from lung metastasis in an interval varying from 4 to 23 years after initial treatment. Brain metastasis are also described in the literature [29].

The treatment of metastatic disease can include single or multiple drugs chemotherapeutic schemas. According to a review of chemotherapy for ACC of the head and neck tumors, the response rates to chemotherapy are low and the response duration is generally short, and no standard chemotherapy regimen is recommended at this time [30]. Yang et al. [16] used six cycles of cyclophosphamide, adriamycin, and cisplatin for one patient with lung metastasis, achieving only stable disease status.

Overall survival of patients with ACCBG varies significantly according to the clinical stage at presentation. Nowak et al. [31] reported the case of a patient who was treated with local excision and positive margins, complemented by a vulvectomy, inguinal lymphadenectomy and adjuvant low dose rate brachytherapy $(24 \mathrm{mCi}$, using radium). She was free of the disease for 7 years, when a local recurrence was identified. The salvage treatment included abdominoperineal amputation of the rectum and distal part of the vagina with sigmoideostomy. A new local recurrence locally excised after one year. She had two more local recurrences identified and locally excised in a period of 3 years and after that a diagnosis of an isolated lung metastasis, also excised. The patient died after 3 years due to multiple lung metastases.

The role for antiestrogen therapy was also suggested by Copeland et al. [3] as 50\% (7/14) patients aged below 42 years had their ACCBG diagnosed in association with pregnancy, but further studies on hormone therapy are still required.

\section{Conclusions}

Although no specific guideline for ACCBG has been yet established, the recommended surgical strategies include wide local excision, simple vulvectomy, radical vulvectomy, and lymph node dissection only if affected or suspected of involvement. Patients with positive margins are at higher risk of local and distant failures and in cases where a re-resection is not indicated, radiotherapy seems to be a reasonable option for local control. Chemotherapy as adjuvant treatment is still under evaluation.

\section{Abbreviations \\ ACC: Adenoid cystic carcinoma; ACCBG: Adenoid cystic carcinoma of the Bartholin's gland; BG: Bartholin's gland; Gy: Gray}

\section{Acknowledgements}

To the research nurse, Ana Carolina Schettini, for helping in sending the draft to the AC Camargo Cancer Center Ethics Committee.

Funding

There was no funding provided for this study.

Availability of data and materials

The data that support the findings of this study are available from https:/www.ncbi.nlm.nih.gov/pubmed.

Authors' contributions

ACAP, MD; PhD was the only responsible for data collection and elaboration of the manuscript.

Ethics approval and consent to participate

This review was approved by the AC Camargo Cancer Center Ethics Committee on September, 2017.

\section{Consent for publication}

I, Antonio Cassio Assis Pellizzon, MD; PhD give my consent for publishing the literature review entitled: The adenoid cystic carcinoma of the Bartholin's gland. A literature review.

\section{Competing interests}

The author declares that there are no competing interests.

\section{Publisher's Note}

Springer Nature remains neutral with regard to jurisdictional claims in published maps and institutional affiliations. 
Received: 9 October 2017 Accepted: 24 January 2018

Published online: 28 February 2018

\section{References}

1. Bernstein SG, Voet RL, Lifshitz S, Buchsbaum HJ. Adenoid cystic carcinoma of Bartholin's gland. Case report and review of the literature. Am J Obstet Gynecol. 1983;147(4):385-90.

2. Nasu K, Kawano Y, Takai N, Kashima K, Miyakawa I. Adenoid cystic carcinoma of Bartholin's gland. Case report with review of the literature. Gynecol Obstet Investig. 2005;59(1):54-8.

3. Copeland L, Sneige N, Gershenson DM, Saul PB, Stringer CA, Seski JC. Adenoid cystic carcinoma of Bartholin gland. Obstet Gynecol. 1986;67(1):115-20.

4. Seaver PR Jr, Kuehn PG. Adenoid cystic carcinoma of the salivary glands. A study of ninety-three cases. Am J Surg. 1979;137(4):449-55.

5. Cardosi RJ, Speights A, Fiorica JV, Grendys EC Jr, Hakam A, Hoffman MS Bartholin's gland carcinoma: a 15-year experience. Gynecol Oncol. 2001;82:247-51.

6. Xing D, Bakhsh S, Melnyk N, Isacson C, Ho J, Huntsman DG, Gilks CB, Ronnett BM, Horlings HM. Frequent NFIB-associated gene rearrangement in adenoid cystic carcinoma of the vulva. Int J Gynecol Pathol. 2016; [Epub ahead of print]

7. Panaccione A, Zhang Y, Ryan M, Moskaluk CA, Anderson KS, Yarbrough WG, Ivanov SV. MYB fusions and CD markers as tools for authentication and purification of cancer stem cells from salivary adenoid cystic carcinoma. Stem Cell Res. 2017:21:160-6.

8. Vallonthaiel AG, Jain D, Singh V, Kaur K, Madan K, Kumar V, lyer VK, Sharma MC. c-Myb Overexpression in cytology smears of Tracheobronchial and pulmonary adenoid CysticCarcinomas. Acta Cytol. 2017;61(1):77-83.

9. Hsu AA, Tan EH, Takano AM. Lower respiratory tract adenoid cystic carcinoma: its Management in the Past Decades. Clin Oncol (R Coll Radiol). 2015:27(12):732-40.

10. Agunbiade MM, Lalehparvar S, Khaladj M. Cutaneous adenoid cystic carcinoma with Perineural invasion diagnosed in the foot: a case report. $J$ Am Podiatr Med Assoc. 2017;107(5):457-60.

11. Finan MA, Barre G. Bartholin's gland carcinoma, malignant melanoma and other rare tumours of the vulva. Best Pract Res Clin Obstet Gynaecol. 2003; 17(4):609-33.

12. Massad LS, De Geest K. Multimodality therapy for carcinoma of the Bartholin gland. Gynecol Oncol. 1999;75(2):305-7.

13. Downs LS, Ghosh K, Dusenbery KE, Cosin JA. Stage IV carcinoma of the BGmanaged with primary chemoradiation. Gynecol Oncol. 2002;87(2):210-2

14. Jung JH, Lee SW, Son SH, Kim CY, Lee CH, Jeong JH, Jeong SY, Ahn BC, Lee J. Clinical impact of 18 F-FDG positron emission tomography/CT on adenoid cystic carcinoma of the head and neck. Head Neck. 2017;39(3):447-55.

15. Anaf $V$, Buxant F, Rodesch F, Simon P, van de Stadt J, Noel JC, van Geertruyden J. Adenoid cystic carcinoma of Bartholin's gland: what is the optimal approach? Eur J Surg Oncol. 1999;25:406-9.

16. Yang SY, Lee JW, Kim WS, Jung KL, Lee SJ, Lee JH, Bae DS, Kim BG. Adenoid cystic carcinoma of the Bartholin's gland: report of two cases and review of the literature. Gynecol Oncol. 2006;100(2):422-5.

17. Wang X, Lu W, Zhu C, Ye F, Xie X. Adenoid cystic carcinoma of Bartholin's gland with lung metastasis: a case report. Eur J Gynaecol Oncol. 2009;30(3): 317-20.

18. Korkontzelos I, Fragkoulidis M, Stavroulis A, Apostolikas N, Terzakis E. Adenoid cystic carcinoma of the Bartholin's gland in a young patient: eight-year follow-up. Eur J Gynaecol Oncol. 2009;30(6):686-8.

19. Lelle RJ, Davis KP, Roberts JA. Adenoid cystic carcinoma of the Bartholin's gland: the University of Michigan experience. Int J Gynecol Cancer. 1994; 4(3):145-9.

20. Alsan $\mathrm{Cl}$, Vinh-Hung V, Eren F, Abacioğlu U. Adenoid cystic carcinoma of the Bartholin's gland: case report and systematic review of the literature. Eur J Gynaecol Oncol. 2011;32(5):567-72.

21. Woida FM, Ribeiro-Silva A. Adenoid cystic carcinoma of the Bartholin gland: an overview. Arch Pathol Lab Med. 2007;131(5):796-8.

22. Rosenberg P, Simonsen E, Risberg B. Adenoid cystic carcinoma of Bartholin's gland: a report of five new cases treated with surgery and radiotherapy. Gynecol Oncol. 1989;34:145-7.

23. Agolli L, Osti MF, Armosini V, De Sanctis V, Valeriani M, Enrici RM. Adenoid cystic carcinoma of Bartholin's gland receiving adjuvant radiation therapy: case report. Eur J Gynaecol Oncol. 2013;34(5):487-8.
24. Takatori E, Shoji T, Miura J, Takeuchi S, Sugiyama T. Chemoradiotherapy with irinotecan (CPT-11) for adenoid cystic carcinoma of Bartholin's gland: a case report and review of the literature. Gynecol Oncol Case Rep. 2012;4:16-9.

25. Di Donato V, Casorelli A, Bardhi E, Vena F, Claudia M, Muzii L, Benedetti Panici P. BGcancer. Crit Rev Oncol Hematol. 2017;117:1-11.

26. Sugiyama T, Nishida T, Hosokawa Y, Ushijima H, Nishimura H, Umezu J. Adenoid cystic carcinoma of Bartholin's gland. A review of the literature and report of a patient. Acta Obstet Gynaecol Jpn. 1984;36(5):829-32.

27. Abrao FS, Marques AF, Marziona F, Abrao MS, Uchoa Junqueira LC, Torloni $H$. Adenoid cystic carcinoma of Bartholin's gland: review of the literature and report of two cases. J Surg Oncol. 1985:30(2):132-7.

28. Anderson RJ, Johnston WW, Szpak CA. Fine needle aspiration of adenoid cystic carcinoma metastatic to the lung. Cytologic features and differential diagnosis. Acta Cytol. 1985;29(4):527-32.

29. Hatiboglu MA, Cosar M, Iplikcioglu AC, Ozcan D. Brain metastasis from an adenoid cystic carcinoma of the Bartholin gland. Case report. J Neurosurg 2005;102(3):543-6.

30. Papaspyrou G, Hoch S, Rinaldo A, Rodrigo JP, Takes RP, van Herpen C, Werner JA, Ferlito A. Chemotherapy and targeted therapy in adenoid cystic carcinoma of the head and neck: a review. Head Neck. 2011:33(6):905-11.

31. Nowak M, Rycel M, Szpakowski M, Kulig A, Sobotkowski J, Dziki A. Interdisciplinary treatment of the patient with adenoid cystic carcinoma of the Bartholin's gland resulting in 15 years' survival: a case report and review of literature. Prz Menopauzalny. 2014;13(5):310-2.

\section{Submit your next manuscript to BioMed Central and we will help you at every step:}

- We accept pre-submission inquiries

- Our selector tool helps you to find the most relevant journal

- We provide round the clock customer support

- Convenient online submission

- Thorough peer review

- Inclusion in PubMed and all major indexing services

- Maximum visibility for your research

Submit your manuscript at www.biomedcentral.com/submit
Biomed Central 